\title{
RESEÑAS
}





\section{Virginia Bertolotti, Magdalena Coll (Coords.). Las formas de decir. La prensa en Uruguay en el siglo XIX. Montevideo: Universidad de la República, 2020, 228 páginas}

Esta obra colectiva, coordinada por las profesoras Virginia Bertolotii y Magdalena Coll, inaugura una nueva etapa en la investigación de la historia del español del Uruguay al abordar la prensa como una fuente de estudio válida. Los trabajos que componen este libro son el resultado del proyecto "Lengua y prensa en el Uruguay del siglo XIX", desarrollado entre 2017 y 2019 y financiado por la Comisión Sectorial de Investigación Científica (CSIC) de la Universidad de la República de Uruguay.

Dicho proyecto continúa la línea de los estudios diacrónicos previos del español del Uruguay, basados en corpus de textos manuscritos extraídos de archivos de los siglos XVIII y XIX. Al profundizar en el género periodístico como fuente de análisis lingüístico-histórico, el proyecto elaboró un nuevo corpus, lo que implicó la selección, la edición filológica y la adecuación informática de casi 2500 textos, la creación de una tipología textual para su clasificación y su incorporación posterior al Corpus Diacrónico y Diatópico del Español de América (CORDIAM). De esta forma, este trabajo no solo arroja nuevos datos sobre el estudio histórico del español en Uruguay, sino que también pone a disposición de la comunidad académica un amplio corpus de prensa uruguaya, abordado desde una renovada perspectiva de análisis.

La selección de dichos textos, extraídos del repositorio Anáforas de la UDELAR, se llevó a cabo siguiendo una periodización (10), previamente empleada en otros estudios históricos del español en el Uruguay, por motivos tanto metodológicos como históricos. Esto permitió observar con más claridad los procesos de cambio lingüístico y situar cada texto en un momento político, social y cultural determinado de la historia del Uruguay. El procesamiento de estos datos, además de la adecuación informática, supuso la creación de una tipología textual, empleada actualmente en el CORDIAM, que adscribe cada uno de los documentos a una tipología textual concreta: comentativa, informativa o publicitaria.

Esta obra colectiva reúne un total de siete trabajos, divididos en tres secciones: en la primera (Lengua y discurso en la prensa del siglo XIX) se discute sobre géneros, tradiciones discursivas y usos lingüísticos; en la segunda (Léxico y gramática en la prensa del siglo XIX) se abordan cuestiones de léxico y sintaxis, manteniendo la relación con aspectos textuales de la prensa; y en la tercera (Sobre la prensa del siglo XIX) se incluyen trabajos centrados en la prensa del Uruguay del siglo XIX.

En el primer capítulo, "El fruto de sus predecesoras" (19-42), Hernán Viera (39) constata cómo la construcción y la evolución de los géneros de prensa en Uruguay tienen su fundamento en unas tradiciones discursivas ajenas al ámbito periodístico, entendidas estas como permanencias lingüísticas que se explican histórico-culturalmente. Además de presentar las características generales de la prensa uruguaya del siglo XIX, Viera estudia cómo los editores del momento reproducían recursos de comunicación pero también creaban a través de la adaptación de formas discursivas cuyo manejo ya conocían, como las proclamas, los alegatos jurídico-políticos, los partes de guerra, los bandos públicos o las crónicas de viajes. Asimismo, Viera señala que aquellas noticias que no contaban con una tradición discursiva en la que inscribirse carecían de una forma precisa, como es el caso de las noticias sobre acontecimientos sociales, las reseñas de actividades artísticas o los anuncios publicitarios. Este trabajo demuestra que los editores no tomaban modelos arbitrarios, sino que escogían formatos 
concretos de otras tradiciones discursivas que les permitiesen expresar con comodidad la información y ser interpretados por el lector.

El segundo capítulo, "Los tratamientos plurales en la prensa emergente en el Uruguay del siglo XIX" (43-70), elaborado por Virginia Bertolotti, tiene como objetivo describir el uso de los plurales pronominales vosotros y ustedes y de sus formas verbales cantáis, venís, partís, comparando los datos de la prensa uruguaya del siglo XIX con aquellos provenientes de otras fuentes, que constatan la desaparición de vosotros en contextos cotidianos en América ya en el siglo XVIII. El trabajo se organiza en función de tres variables esenciales: combinatoria sintagmática de pronombres y formas nominales, tipos textuales y géneros discursivos. Atendiendo al punto de vista genérico, la aparición de vosotros se localiza en géneros discursivos planificados y no ficcionales, con contenidos emotivos, como prospectos, editoriales, cartas de lectores, notas de despedida, proclamas, notas de opinión o discursos castrenses. Los datos expuestos por Bertolotti (64) también son prueba de que los medios de comunicación, aunque pueden ser potenciadores de un cambio lingüístico, no son necesariamente el ámbito que garantiza su éxito, pues la historia de vosotros en América no culminará hasta varias décadas después, a pesar de la vitalidad observada en la prensa del siglo XIX.

La segunda sección se abre con el capítulo "«Es mas comercial, mas, fin de siécle»: extranjerismos en la prensa del Uruguay de fines del siglo XIX" (71-108), elaborado por Magdalena Coll y Mayte Gorrostorrazo. Este capítulo se centra en el léxico atendiendo a los extranjerismos que aparecen en la prensa uruguaya del último cuarto del siglo XIX. Las autoras caracterizan estos extranjerismos en función de tres parámetros: según su lengua de origen (inglés, francés, italiano, alemán, portugués), según el tipo de texto en el que aparecen (comentativo, informativo o publicitario) y según su estructura (unidades léxicas simples, unidades fraseológicas y unidades más complejas) (71). Tras análisis de los extranjerismos en general, sin concentrarse en un área léxica particular ni en una lengua extranjera específica, se comprueba que el francés fue la lengua que hizo más aportes a la prensa uruguaya de fines del siglo XIX, que los textos más permeables a los extranjerismos fueron aquellos de tipo comentativo y que la categoría gramatical predominante es la unidad léxica simple. Las autoras explican la incorporación de estos extranjerismos por la asociación de la lengua francesa, así como otras lenguas europeas, a valores de prestigio y distinción social, al tiempo que su presencia en la prensa se constituyó como una preferencia estilística característica de este medio de comunicación (90).

El cuarto capítulo, titulado "El pretérito perfecto compuesto en el español uruguayo del siglo XIX" (109-142) y elaborado por Soledad Álvarez, está dedicado al estudio diacrónico del pretérito perfecto compuesto (PPC) rioplatense, a través dos corpus diferenciados de español uruguayo del siglo XIX: un corpus de documentos manuscritos y otro de prensa. Los resultados del análisis, poniendo foco en la diversidad textual, indican que la escrituralidad favorece el empleo de formas del pretérito perfecto compuesto. La autora muestra cómo el uso del PPC en la prensa periódica aparece en pasajes de carácter comentador o evaluativo, mientras que sus formas competidoras, las del pretérito perfecto simple (PPS), se presentan en pasajes de carácter narrativo (122-136). Además, comprueba que el PPS es capaz de expresar en el español del siglo XIX los valores tradicionalmente adscriptos al PPC. Los resultados presentados en este capítulo (137) permiten tener un conocimiento más preciso del cambio en el empleo de estas dos formas verbales del pasado, cuyas frecuencias y valores de uso son un rasgo caracterizador de la mayor parte de las modalidades americanas del español y las distinguen del español europeo. 
En el capítulo cinco, "Descripción y cronología de las relativas explicativas de atributo antepuesto en documentos de archivo y de prensa del Uruguay en los siglos XVIII y XIX” (143-168), Macarena González Zunini expone los resultados del análisis de relativas explicativas con su atributo antepuesto («Juan Antonio Artigas, vecino que fue de Buenos Ayres»), estudiadas en dos corpus cuantitativamente comparables, ambos del Uruguay actual y tomados del CORDIAM: uno de documentos manuscritos de los siglos XVIII y XIX y otro de prensa del siglo XIX. Estas relativas explicativas se caracterizan, como indica González Zunini (144), por la frontalización del atributo, que se desplaza a la periferia izquierda de la oración a una posición de tópico. La construcción, de aparición esporádica, se registra desde 1726 y se documenta por última vez en 1879 en un documento periodístico. El estudio incluye también otras estrategias sintácticas similares: [Sintagma determinante (sd) [sustantivo (n) + que + ser + de + sd]]. A través de este trabajo, González Zunini aporta una descripción gramatical detallada de este tipo de construcciones, así como una datación y un análisis de los tipos de documentos en los que aparecen.

La tercera y última sección del libro trata sobre la prensa decimonónica del Uruguay. En el capítulo seis, titulado "De los primeros catálogos a la historiografía Contemporánea" (169-194), Wilson González Demuro examina, desde una perspectiva crítica, la producción historiográfica sobre la prensa periódica uruguaya, desde el siglo XIX hasta la actualidad. Además, aborda consideraciones vinculadas con el campo disciplinario de los estudios históricos sobre medios. El autor no se limita a mostrar los estudios previos, sino que propone una periodización del proceso estudiado, prestando particular atención a las continuidades, rupturas, frecuencias temáticas y aspectos teórico-metodológicos destacables. Su análisis (187) nos permite ver cómo los nuevos estudios van dotando a la historia de la prensa de un mayor carácter académico y profesional y que todavía hay un largo camino que recorrer en la historiografía uruguaya sobre los medios de comunicación escrita.

Joaquín Ginés en el capítulo siete, "Dieciocho periódicos del siglo XIX en Uruguay, en pocas palabras" (195-225), describe cronológicamente los dieciocho periódicos que formaron parte del corpus del proyecto de investigación "Lengua y prensa en el Uruguay del siglo XIX”. En su trabajo, Ginés recoge las características principales y sistematiza la información relevante de cada uno de estos periódicos (195). La presentación del contenido de cada periódico se divide en tres secciones principales: 1) orígenes (que describe las condiciones en las que surge el periódico), 2) estilo y tópicos (que refiere a los temas recurrentes, las secciones u organización usual y la forma de abordar los temas) y 3) recepción (que informa sobre los costos y los lugares de adquisición de los números publicados). Gracias a este trabajo se consigue ordenar y clarificar el panorama de la prensa uruguaya, caracterizada por ser heterogénea, diversa, fragmentada y efímera.

Esta obra colectiva supone un gran aporte al estudio de lingüística histórica por varios motivos. En primer lugar, porque aborda el estudio de un corpus de cerca de 2500 textos de prensa «uruguaya» (unas 784872 palabras) y lo pone a disposición de la comunidad académica a través del CORDIAM. En segundo lugar, porque contribuye al mejor conocimiento del proceso de constitución de los géneros periodísticos en la prensa nacional y, a su vez, comprender mejor las relaciones entre género, tradición discursiva y cambio lingüístico. En tercer lugar, porque aporta información pertinente para el estudio de la historia del español del Uruguay y realiza una precisa descripción de la prensa uruguaya del siglo XIX. En cuarto lugar, porque incorpora fuentes poco exploradas todavía en los estudios lingüístico-históricos, reafirmando así la validez de la diversificación de fuentes y del trabajo interdisciplinario. 
En definitiva, los trabajos recogidos en esta obra no solo demuestran que el género periodístico es apropiado para el estudio de la historia del español del Uruguay, sino que plantean nuevos retos y abren la puerta a futuras investigaciones del español americano basadas en distintas fuentes, entre ellas las literarias.

\section{Paula Albitre \\ Universidad Complutense de Madrid \\ Madrid, España}

\section{Brigitte Adriaensen y Carlos van Tongeren (Eds.). Ironía y violencia en la literatura latinoamericana contemporánea. Pittsburgh: Instituto Internacional de Literatura Iberoamericana, 2018, 355 páginas}

Con un estudio introductorio a manera de balance crítico, Brigitte Adriaensen y Carlos van Tongeren (7-19) precisan el vínculo de la ironía, y otros matices aledaños como pueden ser el cinismo, el absurdo, la parodia y el humor negro, con las formas y las prácticas de violencia. De la ironía como tropo, que juega con el desvío de sentido en contraste o en oposición, a la estrategia discursiva que implica tanto la ambigüedad como la distancia, la ironía dispara la polisemia y el contrasentido, para que tenga un "claro potencial político" (8) y se decante por una evaluación o juicio crítico, siempre atribuido al destinatario (ironía de situación) o a una persona (ironía verbal). Esta dimensión axiológica es la que conlleva un "fuerte filo" que actúa sarcástica o descarnadamente (recuerden su origen etimológico en la acción de quitarle la carne a uno, a pedacitos). Porque desencadena en el receptor emociones y libera efectos dispares siempre reprimidos que se activan, el vínculo con el contexto situacional y la efectividad comunicativa hacen que la ironía intente buscar complicidad y consenso a la vez, de modo que comparte con el humor y la risa "su función como puente emocional y como constructora de emociones" (8); de ahí su papel terapéutico y catártico, que Adriaensen y van Tongeren le otorgan en sociedades altamente quebradas y traumatizadas por la violencia tales como la mexicana o la argentina, en donde su reacción es imprevisible y de "doble filo", a saber, contestaria o reaccionaria, emancipatoria o cosificadora, incluyente o excluyente.

En relación con la violencia, los dos editores no encuentran estudios sobre la ironía y la violencia en un contexto latinoamericano; apenas se ha abordado la temática para que este libro cobre su relieve y su pertinencia. Más bien ellos apuntan a un contexto más global para matizar posibles líneas de acción: por ejemplo, el potencial del humor se ha analizado en el contexto de conflictos y guerras contemporáneas, para que su "performance" (10) renueve ante todo la protesta política. También se encuentra el paradigma de los estudios sobre el trauma, en donde el humor sirve para explorar el problema del holocausto con el análisis de chistes y otras prácticas culturales: la relajación ante un tema tan sórdido provoca un escape y un disenso a la vez.

De esta manera, insisten los editores, no se ha prestado la atención necesaria al papel y a la función de la ironía ante el desarrollo de la violencia y es allí en donde lanzan su hipótesis de trabajo que yo resumo de la siguiente manera porque la suya no me parece tan clara: la violencia genera no solo un conflicto, sino también una crisis y un trauma que solamente puede experimentarse otra vez de forma indirecta por medio de una reconstrucción "ficticia" o "no real", hacerla de otra manera (volverla a experimentar en forma literal conduciría a lo 